\title{
Journal of Fisheries and Aquaculture Development
}

\section{Formation of Siamese Catfish, Pangasianodon hypophthalmus, Sauvage, 1878 (Pangasiidae; Siluriformes) F2 Based on Selec- tion of Character Growth}

\author{
Suharyanto* \\ Jadmiko Darmawan dan Evi Tahapari, Research Institute for Fish Breeding, Sukamandi, West Java, Indonesia
}

"Corresponding author: Suharyanto, Jadmiko Darmawan dan Evi Tahapari, Research Institute for Fish Breeding, Sukamandi, West Java, Indonesia. Email: suhar.yanto83@ymail.com

Citation: Suharyanto (2017) Formation of Siamese Catfish, Pangasianodon hypophthalmus, Sauvage, 1878 (Pangasiidae; Siluriformes) F2 Based on Selection of Character Growth. J Fish Aquac Dev: JFAD-115. DOI:10.29011/JFAD-115/100015

Received Date: 30 July, 2017; Accepeted Date: 15 August, 2017; Published Date: 24 August, 2017

\begin{abstract}
Research on the formation of Siamese catfish F2 is one part of the assembly of superior strains of catfish. The research objective is to get a prospective parent of siamese catfish F2 selection results based on character growth. In 2015, the parent has done spawning populations F1 selection results the previous year and the parent population control. F2 seedling population resulting from the breeding between relatives maintained separately from the parent population selection and control. Siamese catfish seedling populations F2 consists of 10 family selection and eight families control in cohort 1 were then used as material selection in this year's study. Selections are made at the age of 11 months of age and the selection differential values obtained siamese catfish F2 cohort 1 are selected by $281.57 \mathrm{~g}$ which means that the average weight of the population of selection increased by $30.82 \%$. In this year also made the establishment of seedling populations of catfish Siamese F2 consisting of 10 families and 3 families of selection on the control cohort 2 were then used as material selection in research in 2017. The population of siamese catfish F2 selection had a higher growth performance than the control. Values response character selection on body weight siamese catfish populations F2 cohort 1 aged 11 months in the amount of $21.34 \%(\Delta \mathrm{G}=164.21 \mathrm{~g})$ and the siamese catfish populations F2 cohort 25 months of age in the amount of $10.50 \%(\Delta \mathrm{G}=10.47 \mathrm{~g})$, so that the known value of the selection response average in the population of siamese catfish F2 of $15.92 \%$. F2 siamese catfish population has the potential to be proposed as a candidate for release catfish is superior because it has the combined value of the selection response $\geq 30,00 \%$, the combined value of the selection response between populations of siamese catfish F1 and F2 Siamese catfish population of 36.83\%.
\end{abstract}

Keywords: F2; Growth Character; Siamese Catfish (Pangasius hypophthalmus) selection

\section{Introduction}

Siamese catfish (Pangasius hypophthalmus) is one of the freshwater fishery commodities that has been cultivated by the community and became one of the flagship product to be developed on the export market. During the years 2007-2009 the average increase in production of commodities catfish is always above 50 percent per year and is expected to catfish production Indonesia is able to reach 1.8 million tons per year in 2014. Very good prospects need to be supported by increasing Siamese catfish production in order to achieve the expected target. One effort to meet the target Siamese catfish production is genetic quality improvement program through selection in order to produce a population with individuals who excel. Selection techniques in fish done in an attempt to alter the average performance of the population to be better in the next generation [1]. Selection is a breeding program that utilizes the diversity of phenotypes (phenotipic variance) that is passed on from parent to offspring [2]. The diversity of the phenotype is the summation of genetic diversity, the diversity of the environment and the interaction between genetic and environmental variation. Further stated that the selection techniques in fish done in an attempt to alter the average performance of the population to be better in the next generation. According Hardjosubroto (1994) [3], the performance of the population is determined by two factors: genetic and environmental factors. 
Citation: Suharyanto (2017) Formation of Siamese Catfish, Pangasianodon hypophthalmus, Sauvage, 1878 (Pangasiidae; Siluriformes) F2 Based on Selection of Character Growth. J Fish Aquac Dev: JFAD-115.

Tave (1995) [2] explains that the selection of qualitative phenotypes in fish is a selection of fish sightings or traits that can be measured, controlled by many pairs of genes and influenced by the environment. The parameters that can be measured by the length of the body, weight, percentage of meat, fat, protein, fecundity, and so forth. Growth is relatively effective parameters used to evaluate the effect of selection on the performance improvement of the population. Selection is done on fish consumption based on character growth, one of which is the weight of the body.

Based on the description above, has done research establishment Siamese catfish (Pangasius hipopthalmus) F2 with the aim to improve the performance of catfish Siamese F1 and F2 generation which has resulted in the growth of better characters.

\section{Materials and Methods}

\section{Research design}

Selection is done is the selection in the family (within the family) where each family that has been formed will be selected for each individual in the family that grow faster. Selections are made at the time of consumption size and then have each of males and females who have the character grow faster.

\section{Selection scheme is carried out as follows:}

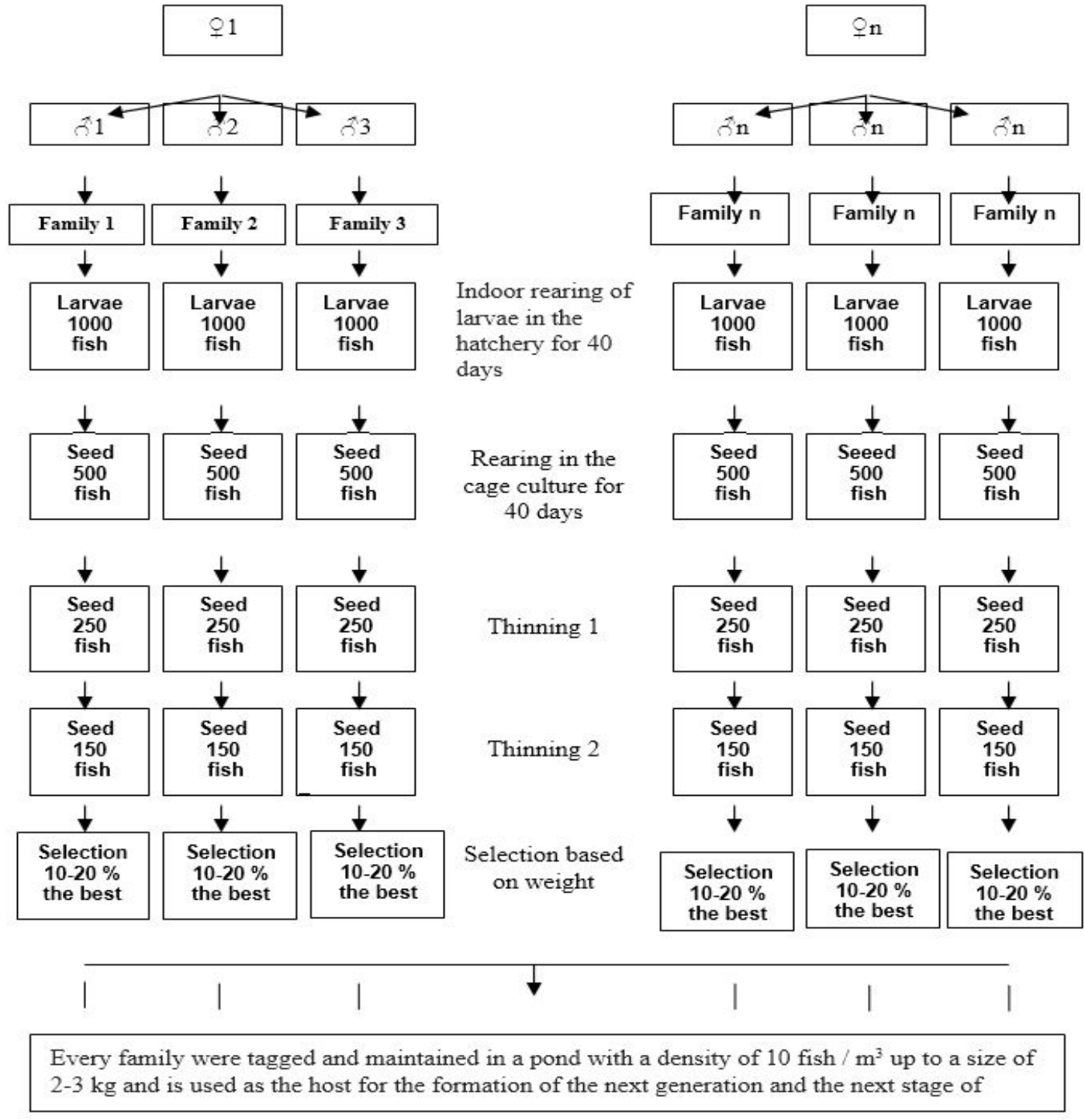

Figure 1: Schematic flow diagram of the selection process Siamese catfish in the Research Institute for Fish Breeding, Sukamandi. 


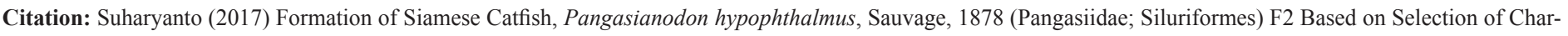
acter Growth. J Fish Aquac Dev: JFAD-115.

In 2016 there were two main activities conducted research, namely

- Selection of F2 population of Siamese catfish cohort 1.

- Establishment of Siamese catfish F2 population cohort 2 material selection.

\section{Materials and Equipment}

Materials and tools necessary for research activities are:

Ingredients: Artemia, feed (Siamese catfish mother, seed and enlargement), hormonal (HCG and ovaprim), tubifek, water fleas, Tagg (microchip), catheter, frame nets, waring a lid, the installation of aeration and drugs.

Tools: WQC to measure water quality parameters, scales, rulers, tools fisheries; seser (catching tool), buckets, syringes, thermometers maximum, minimum.

\section{Procedure Research}

Selection of F2 population of Siamese catfish cohort 1

\section{Fish Test}

Test fish is siamese catfish F2 population cohort 1 material selection in 2015 consisting of 10 family selection, with the amount of each family as much as 150 fishes. Selections are made at the time of test fish reach the size of consumption with an average body weight $\geq 750 \mathrm{~g} /$ fish.

\section{Containers Rearing}

Rearing Siamese catfish F2 population cohort 1 material selection are cultured on the cage size of $5 \times 3 \times 1.25 \mathrm{~m} 3$ which is located in an area of $6000 \mathrm{~m} 2$ with a net density of 150 fish / cage. After the selection, selected fish populations and fish origin populations are cultured at the pond wall the size of $200 \mathrm{~m} 2$ with a water depth of 1.20 to $1.50 \mathrm{~m}$.

\section{Rearing test fish}

Feed for cultured activities Siamese catfish populations F2 material selection until the test fish is ready to be selected using commercial feed with a protein content of $30 \%$ as much as $3 \%$ weight of biomass per day. After the selection, selected fish populations and native fish populations were fed a commercial pellet with $36 \%$ protein content as much as $2 \%$ weight of biomass per day. Feed given by the frequency 2 times a day in the morning and evening.

\section{Implementation Selection}

Crosses using half-sib pattern of the one female parent were fertilized two male parent. In this experiment, 20 families of catfish Siamese obtained from the cross 10 mated with a female parent male parent 20. The selection method used is selected families/ within family selection [2]. Selections are made at the time of consumption size ( $\geq 750 \mathrm{~g} / \mathrm{fish})$. During the maintenance period catfish conjoined to measure the consumption of thinning and observation of the growth of each month to determine the feeding rate.

\section{The parameters observed}

Parameters measured were growth of catfish conjoined covering a total length, standard length and weight of the average individual and genetic parameters include the coefficient of diversity and selection response.

\section{Establishment of catfish Siamese F2 population cohort 2 material selection}

\section{Parent Fish Test}

Parent test fish needed in the formation of Siamese catfish F2 population cohort 2 material selection. Parent fish samples used in this study is the parent Siamese catfish F1 contained in the pond of Research Institute for Fish Breeding [4]. Total of Siamese catfish parents are used as many as 10 females and 20 males mature gonads and ready to spawned. All parent used is a parent who has been marked with (Tagging) using a microchip on previous research in order to know his pedigree to avoid inbreeding at the time of formation of Siamese catfish F2 population cohort 2.

\section{Containers Rearing}

Rearing of parent fish of siemese catfish F1 were conducted at the experiment pond of Research Institute for Fish Breeding, Sukamandi. Rearing of the parent container is a pond measuring $400 \mathrm{~m} 2$ with water depth from 1.00 to $1.20 \mathrm{~m}$. In order to obtain good growth, Oxygen Condition strived $>3 \mathrm{ppm}$. After be conducted formation population of Siamese catfish F2 cohort 2, larvae reared in indoors hatchery using fiber tank round container rearing of volume capacity $700 \mathrm{~L}$ with water volume rearing were 200L and larval density of 100 fish / L. Rearing operations as indoor hatchery and conducted for two months. Furthermore, larvae reared in the net cages size $3 \times 3 \times 1.25 \mathrm{~m} 3$, its located on the pond area with nets cages of $6,000 \mathrm{~m} 2$ density of 1,000 fish / net cage for 40 days.

\section{Feed}

As for the rearing of simese catfish parent, the feed given commercial pellet with $36 \%$ protein content as much as $1 \%$ weight of biomass per day. Feed given by the frequency 2 times a day. Feed for enlargement activities F2 population of Siamese catfish materials selection using commercial feed with a protein content of $30 \%$ as much as $3 \%$ of weight biomass per day.

\section{Spawning}

Spawning done artificially by using hormonal stimulation with two stage injection. The female parent was given the first in- 


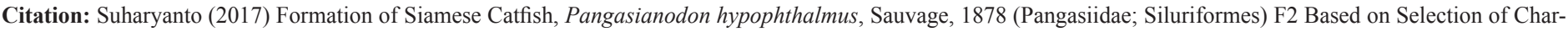
acter Growth. J Fish Aquac Dev: JFAD-115.

jection in the form of HCG with a dosage of $500 \mathrm{IU} / \mathrm{kg}$ of weight. The second injection is given with an interval of 24 hours in the form of ovaprim with a dosage of $0.6 \mathrm{ml} / \mathrm{kg}$ weight. Striping to obtain egg cells do 10-12 hours from the second injection. To get the sperm, the male parent was induced by injection of hormones ovaprim a dosage of $0.2 \mathrm{ml} / \mathrm{kg}$ weight. Striping for sperm retrieval is done 10-12 hours after injection.

Eggs and sperm are removed by means of massaging the abdomen (stripping) toward urogenital. Eggs collected in a bowl, while the sperm is collected using sample bottles $250 \mathrm{ml}$ volume. To maintain the quality of sperm, sperm preserved with a given physiological solution $(\mathrm{NaCl} 0.9 \%)$ with a ratio of $1: 10$. Artificial fertilization is done by mixing the eggs with the sperm as much as $300 \mathrm{~g}$ of $20-30 \mathrm{ml}$, then stirred evenly using chicken feathers for 30 seconds. Furthermore, activated with oxygen-rich water that is put into a bowl (aqua mineral water) while stirring. Then the rest of the sperm removed until clean, then egg fertilization outcome was rinsed with water to remove the soil layer adhesion glycoproteins to eliminate the eggs, then eggs cleaned rinsed with clean water. Subsequently incubated eggs hatching using a funnel at a temperature of $28^{\circ} \mathrm{C}$.

\section{Rearing of larvae and Seed}

The larvae of spawning results are reared in fiber tanks (inhatchery) for 2 months (up to a size of 2 inches). Feed used for the rearing of larvae and seeds are nauplius of Artemia sp., Frozen water fleas, Tubifex sp. and artificial feed in the form of crumbs with a crude protein content of $40 \%$.

After 2 months old seed reared in the net cage measuring of $3 \times 3 \times 1.5 \mathrm{~m} 3$ in the culture pond size of $6000 \mathrm{~m} 2$. Artificial feed in the form of a powder with a protein content of $40 \%$ given feed ad libitum, with a time of 2 times per day. After 40 days of rearing thinning to $250 \mathrm{fish} / \mathrm{net}$ cage. Further test fish were fed artificial / floating pellet feed with $30 \%$ protein content were provided ad libitum, with a time of 2 times per day.

Thinning is done during the nursery I, separating II and magnification up to $500 \mathrm{~g}$ medium-sized fish. During the reared period was observed on growth. Selection will be done once during sized fish $\geq 750 \mathrm{~g}$ and have $10 \%$ of Siamese catfish who had average highest weight. The selection of Siamese catfish population cohort 2 conducted the following year.

\section{Data analysis}

The data obtained were analyzed by univariate GLM using SPSS.

\section{Results and Discussion}

Selection is one of the breeding programs that utilize phenotipic variance (phenotypic diversity) is passed from parent to off spring [2]. In this study, the selection method used is selected in the family (within the family) that is based on the average properties of each individual in each family group. In this selection of each family represented by its best individuals to form the next generation [5].

From this study produced 20 families and 11 families control the selection consists of two cohorts, with cohort 1 and cohort 2 obtained from different spawning time. In cohort 1 was obtained 10 families of 8 families selection and maintenance achieve control by age 11 months, while the second cohort selection and obtained 10 families 3 families control by age 5 months of rearing. Differences in spawning period is due to the difficulty to get a parents mature female gonads in large numbers and the facilities are not adequate.

\section{Formation and selection of siamese catfish F2 cohort 1 and Perform of siamese catfish F2 cohort 1}

Observations on the average standard length and the total length on population selection and control of catfish Siamese F2 cohort 1 produces the Coefficient of Variation $(\mathrm{CV})$ were moderate $(<20 \%)$ while the character of body weight in the population selection and control of yield coefficient of variation (CV) were classified as moderate (20-50\%) (Table 1) [6] states that to determine the diversity of a character used the following criteria: low if CV $(0-20 \%)$, moderate $(20-50 \%)$ and high $(>50 \%)$. The coefficient of variation shows the value of the diversity of the population measured, where the higher the value of the coefficient of variation showed that the population measured have a broad diversity or more heterogeneous, whereas if a lower variation coefficient means the population being measured has a value of diversity narrower or more homogeneous. In the clinical population have seen that the character length variation coefficient smaller than the character's body weight, it suggests that the character length is more homogeneous or have a narrow diversity than its weight. This indicates that the selection is more effectively done on the character of body weight have a higher diversity.
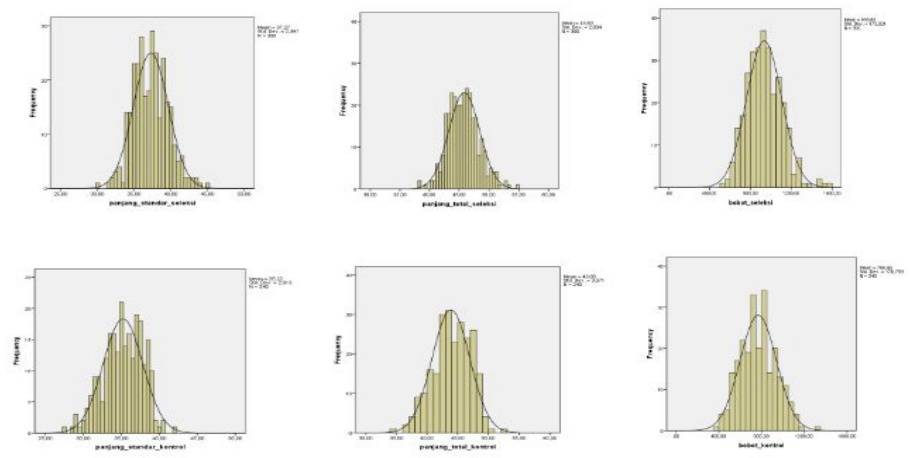

Figure 6: The distribution pattern of standard length, total length and weight of selection and population control population of catfish Siamese F2 cohort 1. 


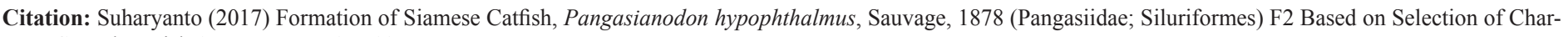
acter Growth. J Fish Aquac Dev: JFAD-115.

The distribution pattern or distribution of standard length, total length and weight of the individual on the selection and population control population of Siamese catfish F2 cohort 1 are presented in (Figure 6). In the distribution curve shows that the distribution of data for catfish Siamese F2 population cohort 1 is on the right selection of data distribution population control. This shows an increase in performance compared to a control population selected population.

\begin{tabular}{|c|c|c|c|c|c|c|}
\hline \multirow{3}{*}{ Remark } & \multicolumn{6}{|c|}{ Variable } \\
\hline & \multicolumn{2}{|c|}{ Standard length $(\mathrm{cm})$} & \multicolumn{2}{|c|}{ Total length $(\mathrm{cm})$} & \multicolumn{2}{|c|}{ Body weight (g) } \\
\hline & Selection & Control & Selection & Control & Selection & Control \\
\hline Sample value /N (fish) & 300 & 300 & 300 & 300 & 300 & 300 \\
\hline Maximaum value & 45 & 42 & 55 & 52 & $1,576.00$ & $1,340.00$ \\
\hline Minimum value & 30 & 27.5 & 43.3 & 34 & 556 & 396 \\
\hline Mean value & 37.27 & 35.22 & 45.83 & 43.88 & 933.85 & 769.65 \\
\hline Standard of deviation & 2.4 & 2.61 & 2.6 & 3.07 & 173.02 & 170.79 \\
\hline Coefficient of Variation (\%) & 6.43 & 7.42 & 5.68 & 7 & 18.53 & 22.19 \\
\hline Genetic Gain $(\Delta G)$ & & 2.05 & & 1.95 & & 164.21 \\
\hline Response of Selection (\%) & & 5.81 & & 4.44 & & 21.34 \\
\hline
\end{tabular}

Table 1: The mean, standard deviation, coefficient of variation, genetic gain and selection response selection and population control population Siamese catfish F2 cohort 1 aged 11 months.

The success of the selection can be measured from the value of genetic progress (genetic gain) Selection response generated. Genetic progress or expected response to selection per year as a result of the selection is dependent on the intensity of selection, genetic diversity, the diversity of phenotypes and generation interval $[3,5,7,8]$. The optimal combination of these factors it is necessary to obtain optimal genetic progress [3,5]. According to Gjedrem (2000) [9] estimated genetic progress or response per generation of selection for aquatic organisms ranging from 10 to $20 \%$. The results obtained showed that the response of Siamese catfish selection in F2 cohort 1 to the character of body weight has a value and a strong selection response that is equal to $21.34 \%$ with the amount of genetic progress $(\Delta \mathrm{G})$ of $164.21 \mathrm{~g}$ (Table 1). This value is higher than previous studies, as presented by Pamungkas, et al. (2014) [10], which explained that the selection by showing the value of the response character selection body weight in F1 Siamese catfish population cohort 1 aged 14 months in the amount of $27.71 \%(\Delta \mathrm{G}=163.26 \mathrm{~g})$ and the catfish population conjoined $\mathrm{F} 1$ age cohort $211 \mathrm{months}$ in the amount of $14.10 \%(\Delta \mathrm{G}=70.67 \mathrm{~g})$, so that the known value of the selection response averages in the population of siamese catfish $\mathrm{F} 1 \mathrm{of} 20.91 \%$.

\section{Selection siamese catfish F2 cohort 1.}

The observation and calculation of the performance, differential selection and heritability values of selected populations and populations of catfish Siamese origin F2 cohort 1 aged 11 months are presented in (Table 2).

\begin{tabular}{|c|c|c|c|c|c|c|}
\hline \multirow{3}{*}{ Remark } & \multicolumn{6}{|c|}{ Variable } \\
\hline & \multicolumn{2}{|c|}{ Standard length $(\mathrm{cm})$} & \multicolumn{2}{|c|}{ Total length $(\mathrm{cm}$} & \multicolumn{2}{|c|}{ Body weight (g) } \\
\hline & Selected & Origin & Selected & Origin & Selected & Origin \\
\hline Sample value/N (fish) & 144 & 144 & 144 & 144 & 144 & 144 \\
\hline Maximum value & 45.5 & 39 & 55 & 48.5 & $1,676.00$ & $1,070.00$ \\
\hline Minimum value & 36 & 34 & 44.5 & 42 & 902 & 708 \\
\hline Mean value & 39.75 & 36.72 & 48.6 & 45.29 & $1,195.06$ & 913.49 \\
\hline Standard of Deviation & 1.83 & 1.2 & 2.28 & 1.35 & 142.19 & 62.31 \\
\hline Coefficient of Variation (\%) & 4.59 & 3.28 & 4.7 & 2.97 & 11.9 & 6.82 \\
\hline Differential of Selection & & 3.04 & & 3.32 & & 281.57 \\
\hline Heritability (h2) & & 1.92 & & 1.34 & & 0.08 \\
\hline
\end{tabular}

Table 2: The mean, standard deviation, coefficient of variation, differential selection and heritability values of selected populations and populations of Siamese catfish origin F2 cohort 1 aged 11 months. 


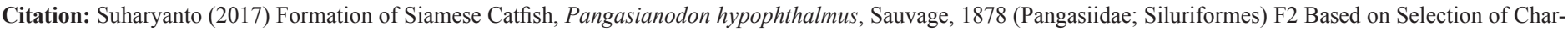
acter Growth. J Fish Aquac Dev: JFAD-115.

In the activity of selection obtained the selection differential values which represents the difference between the weighted average of a selected population and initial population. According to Hardjosubroto (1994) [3], differential selection (selection differential) is the difference between the average performance of a selected population with the average performance of the population before the selection. Selection differential value is one important factor in determining the success of the selection. The higher the differential value of the selection of a population will generate value selection response that the higher assuming that the heritability estimates remain. Selection differential value obtained catfish Siamese F2 cohort 1 are selected by $281.57 \mathrm{~g}$ which means that the average weight of the population of selection increased by $30.82 \%$. It can provide an opportunity to increase the weighted average of catfish conjoined at the next generation in response to the selection made.

Distribution pattern or distribution of standard length, total length and weight of the individual in the population of origin and selected populations of catfish Siamese showing distribution of standard length, total length and weight of the population from which the individual is no equivalent to the population selected (Figure 7). This occurs because of the difference in the size of male and female fish where the fish on top of the size of the fish is dominated by females in pairs, so that the cut off the male fish are below the cut-off average. In addition, the performance of each of the families that are not the same while the selection method used is selected in a family where each family to donate individuals selected also led to the distribution pattern or distribution occurs.
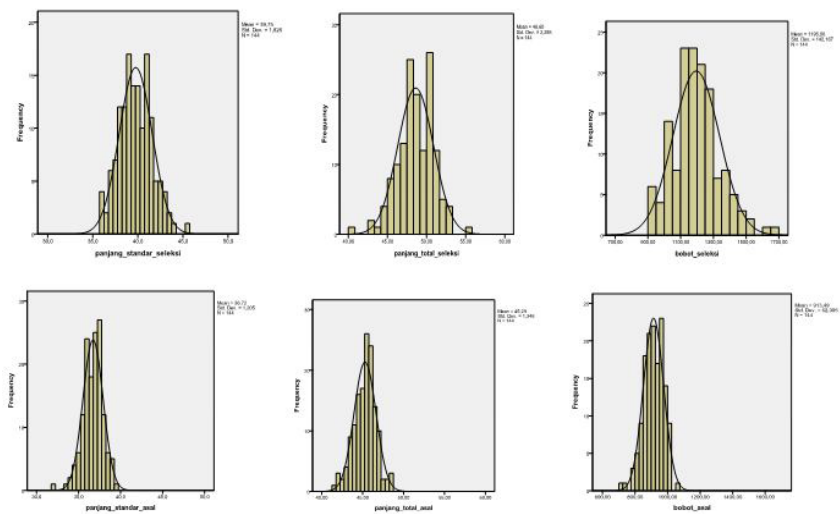

Figure 7: The distribution pattern of the standard length, total length and weight of a selected population and the population from siamese catfish F2 cohort 1.

\section{Siamese catfish population establishment F2 cohort 2 material selection}

Observations on the average standard length and the total length on population selection and control of catfish Siamese F2 cohort 2 produces the Coefficient of Variation (CV) were moderate $(<20 \%)$ while the character of body weight in the population selection and control of yield Coefficient of Variation (CV) were classified as moderate $(20-50 \%)$. Despite having a higher CV value, the resulting pattern on catfish Siamese F2 cohort 2 is similar to Siamese catfish cohort1 F2. In character weight which is a character that is used as a selection parameter, the value of CV on Siamese catfish F2 cohort 2 at 39.90 to $40.50 \%$ while the catfish Siamese F2 cohort $1 \mathrm{CV}$ values obtained at $18.53-22.19 \%$ (Table 3) [6] states that to determine the diversity of a character used the following criteria: low if CV (0-20\%), moderate $(20-50 \%)$ and high $(>50 \%)$. The coefficient of variation shows the value of the diversity of the population measured, where the higher the value of the coefficient of variation showed that the population measured have a broad diversity or more heterogeneous, whereas if a lower variation coefficient means the population being measured has a value of diversity narrower or more homogeneous. In the clinical population have seen that the character length variation coefficient smaller than the character's body weight, it suggests that the character length is more homogeneous or have a narrow diversity than its weight. This indicates that the selection is more effectively done on the character of body weight have a higher diversity [11].

Distribution pattern or distribution of standard length, total length and weight of the individual on the selection and population control population Siamese catfish F2 cohort 2 is presented in (Figure 8). In the distribution curve seen that the distribution of population data for Siamese catfish F2 cohort 2 selections is on the right distribution of data population control. This shows an increase in performance compared to the control population selected population. So that the value of $\mathrm{CV}$ is quite high and the distribution patterns or the distribution generated, Siamese catfish F2 population cohort 2 has a greater chance for selection.

The results obtained showed that the response of siamese catfish selection in F2 cohort 2 at 5 months of age for the character of body weight has a massive genetic progress $(\Delta \mathrm{G})$ of $10.47 \mathrm{~g}$ with a value high enough response Selection of $10.50 \%$ (Table 3 ) although this value is lower than Siamese catfish F2 cohort 1 that reached $21.34 \%$ (Table 1 ). 


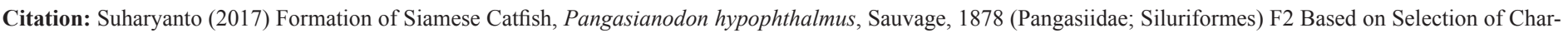
acter Growth. J Fish Aquac Dev: JFAD-115.
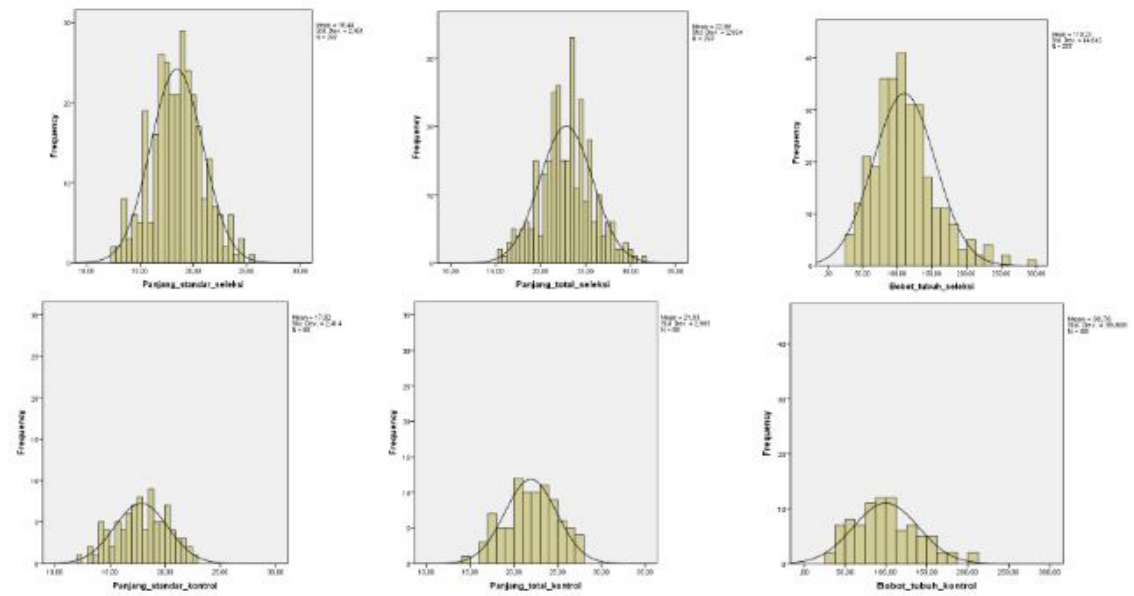

Figure 8: The distribution pattern of the standard length, total length and weight of a selected population and the population from Siamese catfish F2 cohort 1 .

\begin{tabular}{|c|c|c|c|c|c|c|}
\hline \multirow{3}{*}{ Remark } & \multicolumn{6}{|c|}{ Variable } \\
\hline & \multicolumn{2}{|c|}{ Standard length $(\mathrm{cm})$} & \multicolumn{2}{|c|}{ Total length(cm) } & \multicolumn{2}{|c|}{ Body weight (g) } \\
\hline & Selection & Control & Selection & Control & Selection & Control \\
\hline Sample value/N (fish) & 297 & 88 & 297 & 88 & 297 & 88 \\
\hline Maximum value & 25.5 & 22.5 & 31.5 & 27.7 & 299.00 & 202.00 \\
\hline Minimum value. & 12.7 & 12.2 & 15.7 & 14.7 & 30 & 28 \\
\hline Mean value & 18.44 & 17.82 & 22.86 & 21.93 & 110.23 & 99.76 \\
\hline Standard of Deviation & 2.45 & 2.41 & 2.95 & 2.96 & 44.64 & 39.81 \\
\hline Coefficient of Variance (\%) & 13.29 & 13.54 & 12.92 & 13.52 & 40.5 & 39.9 \\
\hline Genetic Gain $(\Delta \mathrm{G})$ & & 0.62 & & 0.94 & & 10.47 \\
\hline Response of Selection (\%) & & 3.48 & & 4.27 & & 10.5 \\
\hline
\end{tabular}

Table 3: The mean, standard deviation, coefficient of variation, genetic gain and selection response selection and population control population Siamese catfish F2 cohort 2 aged 5 months.

With the value of the response selection character of siamese catfish body weight in a population cohort of conjoined F2 1 aged 11 months in the amount of $21.34 \%(\Delta \mathrm{G}=164.21 \mathrm{~g})$ and the Siamese catfish populations F2 cohort 25 months of age in the amount of $10.50 \%(\Delta \mathrm{G}=10.47 \mathrm{~g})$, so that the known value of the selection response averages in the population of Siamese catfish F2 of $15.92 \%$. Thus, the combined value of the selection response between populations of catfish Siamese F1 and F2 Siamese catfish population of $36.83 \%$ [12].

\section{Conclusion}

The population of siamese catfish F2 selection had a higher growth performance than the control. Values response character selection on body weight siamese catfish populations F2 cohort 1 aged 11 months in the amount of $21.34 \%(\Delta \mathrm{G}=164.21$ grams $)$ and the Siamese catfish populations F2 cohort 2, 5 months of age in the amount of $10.50 \%(\Delta \mathrm{G}=10.47$ grams $)$, so that the known value of the selection response averages in the population of sia- mese catfish F2 of $15.92 \%$. Siamese catfish F2 population has the potential to be proposed as a candidate for release siamese catfish is superior because it has the combined value of the selection response $\geq 30,00 \%$, the combined value of the selection response between populations of siamese catfish F1 and F2 Siamese catfish population of $36.83 \%$.

\section{References}

1. Tave D (1986) Genetics for Fish Hatchery Managers. AVI Publishing Co, Westport Conecticut.

2. Tave D (1995) Selective breeding programmes for medium-sized fish farms. FAO Technical Paper 122.

3. Hardjosubroto W (1994) Applications of livestock Breeding On The field. Gramedia Widiasarana Indonesia. Jakarta. (In Indonesian).

4. Gjedrem T, Baransky M (2009) Selective breeding in aquaculture: An introduction. Springer Dordrect Heidenberg London New York 221.

5. Warwick EJ, Astuti dan JM, Hardjosubroto W (1995) Breeding Cattle. Gadjah Mada University Press. Yogyakarta (in Indonesian) 
Citation: Suharyanto (2017) Formation of Siamese Catfish, Pangasianodon hypophthalmus, Sauvage, 1878 (Pangasiidae; Siluriformes) F2 Based on Selection of Character Growth. J Fish Aquac Dev: JFAD-115.

6. Tampake HD, Pramono dan HT, Luntungan (1992) Phenotypic diversity Qualities Generative and Component Fruit Some Types of Coconut Peat Tidal, South Sumatra. Buletin Balitka 18: 21- 26.

7. Lasley JE (1978) Genetics of Livestock Improvement. Prentice Hall Inc. Englewood Cliffs, New Jersey.

8. Dalton DC (1980) An Introduction ti Practical Animal Breeding. $2^{\text {nd }}$ Edition. English Language Book Sociaty. London.

9. Gjedrem T (2000) Genetic improvement of cold-water species. Aquaculture Research 31: 25-33.
10. Pamungkas W, Darmawan J, Nurlaela I, Dewi dan E RRSPS, Tahapari (2014) Performance of growth and response to selection of striped catfish (Pangasianodon hypophthalmus) F2. Research Report. Research Institute for Fish Breeding, Sukamandi, West Java (In Indonesian) 14.

11. W (1996) Genetics. Fift edition. Tarsito. Bandung (In Indonesian) 397.

12. Reddy RP (1996) Symposium: The Effect of Long-Term Selection on Growth of Poultry. Poultry Sci 75: 1164-1167. 